\title{
Strengthening of Ti-6Al-7Nb alloy by high-pressure torsion processing
}

\author{
M. Ashida ${ }^{1}$, P. Chen ${ }^{1}$, Y. Tsutsumi ${ }^{1}$, T. Hanawa ${ }^{1,}{ }^{*}$, Z. Horita $^{2,3}$ \\ ${ }^{1}$ Institute of Biomaterials and Bioengineering, Tokyo Medical and Dental University, 101-0062 Tokyo, Japan \\ 2 Department of Materials Science and Engineering, Kyushu University, 819-0395 Fukuoka, Japan
}

${ }^{3}$ WPI, International Institute for Carbon-Neutral Energy Research (WPI-I2CNER), Kyushu University, 819-0395 Fukuoka, Japan

*hanawa.met@tmd.ac.jp

\begin{abstract}
$\underline{\text { Abstract }}$
A Ti-6Al-7Nb alloy with three different initial microstructures was processed by high-pressure torsion (HPT) and the resultant microstructure and mechanical properties of the alloy after HPT processing were investigated. The microstructure of the as-received alloy was an equiaxed $(\alpha+\beta)$ microstructure. The rods were subjected to solution treatment and aging (STA) treatment to obtain a bi-modal microstructure consisting of an equiaxed $\alpha$ phase and lamellar $\alpha+\beta$ phases, and those to solution treatment and quenching (STQ) treatment to obtain a bi-modal microstructure consisting of equiaxed $\alpha$-phase and acicular $\alpha^{\prime}$-phase. Disks were cut from those rods and were processed by HPT under a pressure of $6 \mathrm{GPa}$. After HPT processing through 20 revolutions, the alloy with each of the three initial microstructures showed ultrafine grains with a size of $\sim 70 \mathrm{~nm}$. The alloy resulted in a higher tensile strength (1350 MPa) in both the bi-modal microstructures than that (1250 $\mathrm{MPa})$ in the alloy with equiaxed $\alpha+\beta$ microstructure after HPT processing. It was shown that the Ti-6Al-7Nb alloy with the bi-modal microstructure was strengthened more than with the equiaxed $\alpha+\beta$ microstructure when the alloy was processed by HPT. Furthermore, the alloy with bi-modal microstructure consisting of equiaxed $\alpha$-phase and acicular $\alpha$ '-phase showed a good balance between the tensile strength $(1280 \mathrm{MPa})$ and the elongation to fracture $(22 \%)$ after HPT processing through 1 revolution. In summary, therefore, large strength and elongation of the Ti-6Al-7 $\mathrm{Nb}$ alloy were simultaneously achieved by HPT processing.
\end{abstract}

\section{Introduction}

A Ti-6Al-7Nb alloy is widely used in medicine, such as artificial hip joints, spinal fixators, and dental implants, due to its lightweight and superior corrosion resistance. This alloy can be an excellent alternative of the more widely used Ti-6Al-4V alloy, because vanadium shows cytotoxicity. These alloys have a bi-modal microstructure consisting of $\alpha$ and $\beta$ phases, which result in good balance of mechanical properties for medical applications. However, it is not possible to achieve a significant strengthening of the Ti-6Al-7Nb alloy by a conventional means of quenching and aging treatments.

High-pressure torsion (HPT) is a processing technique to produce ultrafine-grained samples through severe plastic deformation, even for hard and low-ductile metallic materials [1]. It is then anticipated that the mechanical properties can be enhanced significantly by the HPT processing. It was reported that a large volume fraction of the lamellar $\alpha+\beta$ phase leads to 
a high hardness after HPT processing in the Ti-6Al-4V alloy with a bi-modal microstructure [2]. For Ti-6Al-7Nb alloy, it was reported that the ultra-fine grained microstructure can be produced by HPT [3,4], but the mechanical properties after HPT are not well investigated. Our previous study showed that the grain refinement of the Ti-6Al-7Nb alloy with equiaxed microstructure was achieved by HPT processing [5] and the grain-refined Ti-6Al-7Nb alloy had a good cytocompatibility as with the alloy before HPT processing [6].

In this study, the Ti-6Al-7Nb alloy with three different initial microstructures were processed by HPT and the resultant microstructure and mechanical properties were investigated.

\section{Material and experiments}

A commercial Ti-6Al-7Nb alloy (ASTM F1295) was employed in this study. The microstructure for as-received specimen shows an equiaxed $\alpha+\beta$ microstructure with the grain size of $\sim 5 \mu \mathrm{m}$. It is estimated that the volume fraction of $\alpha$ phase was $\sim 95 \%$. The rods of the alloy were subjected to two different heat treatments for solution treatment and aging (STA) and solution treatment and quenching (STQ). The STA condition was solution-treatment at $1258 \mathrm{~K}$ for $1 \mathrm{~h}$, air cooled to room temperature and then given an aging treatment at $973 \mathrm{~K}$ for $4 \mathrm{~h}$ followed by air cooling. The STQ condition was solutiontreatment at $1258 \mathrm{~K}$ for $1 \mathrm{~h}$, followed by quenching in iced water. The solution treatment was conducted at $1258 \mathrm{~K}$ which is lower than $\beta$ transus of Ti-6Al-7Nb alloy [3]. Disks were cut from such rods and were processed by HPT at room temperature under a pressure of $6 \mathrm{GPa}$ with a rotation speed of $1 \mathrm{rpm}$. The number of revolutions $(\mathrm{N})$ imposed on the specimens was 1,5 and 20. For comparison, disks without heat treatment (as-received specimen) were processed by HPT.

The microstructure was characterized using a scanning electron microscope (SEM; S-3400NX, HITACHI) and a transmission electron microscope (TEM; H-7100, HITACHI, and JSM-7100F, JEOL) including an X-ray diffractometer (XRD; D8 ADVANCE, BRUKER AXS). The constituent phases were analysed by XRD with the Cu K $\alpha$ radiation operating at $40 \mathrm{kV}$ and $40 \mathrm{~mA}$. For SEM and TEM observations, an electro polishing was performed using a solution of $5 \% \mathrm{HClO}_{4}$, $35 \% \mathrm{CH}_{4}\left(\mathrm{CH}_{2}\right)_{3} \mathrm{OH}$, and $95 \% \mathrm{CH}_{3} \mathrm{OH}$ at $248 \mathrm{~K}$. SEM was operated at $15 \mathrm{kV}$ and TEM was operated at $100 \mathrm{kV}$ or $200 \mathrm{kV}$.

The mechanical properties of the specimens were evaluated by Vickers microhardness measurement and tensile test. After polishing to a mirror-like surface, the hardness was measured along the 12 radial directions from the center to the edge of each disk in incremental steps of $0.5 \mathrm{~mm}$ under a load of $2.942 \mathrm{~N}$ for $15 \mathrm{~s}$. The average hardness was obtained from 12 measurements at equal distances from the disk center. Tensile specimens were cut from the $10 \mathrm{~mm}$ diameter disks at the position $2 \mathrm{~mm}$ separated from the disk center using an electrical discharge machine. Each tensile test was performed using a tensile testing machine with an initial strain rate of $2 \times 10^{-3} \mathrm{~s}^{-1}$.

\section{Results and discussion}

\subsection{Ti-6Al-7Nb alloy subjected to STA and STQ treatments}

As shown in Fig.1, the initial microstructure shows a bi-modal microstructure consisting of an equiaxed $\alpha$ phase and lamellar $\alpha+\beta$ phases with a grain size of $\sim 10 \mu \mathrm{m}$ for (a) Ti-6Al-7Nb (STA) and a bi-modal microstructure consisting of equiaxed $\alpha$-phase and acicular martensitic $\alpha$ '-phase with a grain size of $\sim 5 \mu \mathrm{m}$ for (b) Ti-6Al-7Nb (STQ). It is estimated that the volume fraction of equiaxed $\alpha$ phase was $\sim 40 \%$ for the alloy (STA) and $\sim 20 \%$ for the alloy (STQ). 
(a)

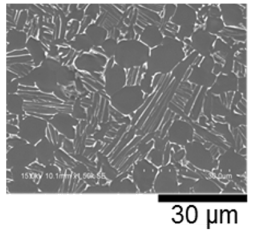

(b)

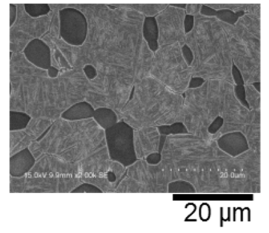

Fig.1. SEM micrographs of Ti-6Al-7Nb alloy with (a) STA treatment and with (b) STQ treatment before HPT processing.

\subsection{Microstructure and mechanical properties of Ti-6Al-7Nb alloy without heat treatment and with STA treatment after HPT}

Figures 2 and 3 show TEM images of Ti-6Al-7Nb alloy without heat treatment and with STA treatment, respectively, after HPT through 5 revolutions. Selected area electron diffraction (SAED) from both images shows a ring pattern, indicating that the microstructures consist of ultrafine grains having high angles of misorientations. After 5 revolutions, the dark-field images reveal that the grain size of $\alpha$ phase and $\beta$ phase for Ti-6Al-7Nb alloy (STA) was $\sim 70 \mathrm{~nm}$ and $\sim 60 \mathrm{~nm}$, respectively, and these were finer than $\sim 90 \mathrm{~nm}$ and $\sim 70 \mathrm{~nm}$ for without heat treatment. In addition, the grain sizes of $\beta$ phase were finer than those of $\alpha$ phase in the both cases of equiaxed microstructure and bi-modal microstructure. This is because of difference in crystal structure. After HPT through 20 revolutions, the grain size of $\alpha$ phase and $\beta$ phase for Ti-6Al-7Nb alloy without heat treatment were $\sim 70 \mathrm{~nm}$ and $\sim 65 \mathrm{~nm}$ and the grain size of $\alpha$ phase and $\beta$ phase for Ti-6Al-7Nb alloy (STA) were $\sim 70 \mathrm{~nm}$ and $\sim 40 \mathrm{~nm}$.

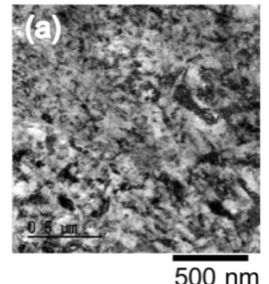

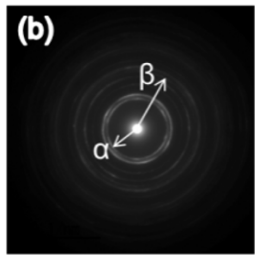

$500 \mathrm{~nm}$
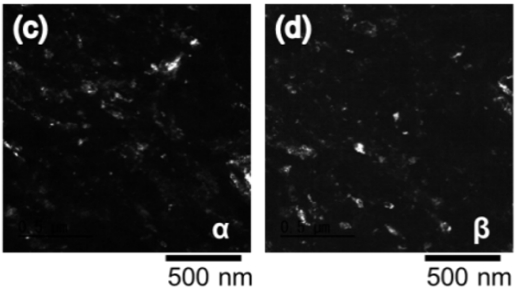

Fig.2. TEM images ((a) bright-field image, (b) SAED pattern and (c), (d) dark-field images of $\alpha$ and $\beta$ phase) of Ti-6Al-7Nb alloy without heat treatment after HPT through 5 revolutions.

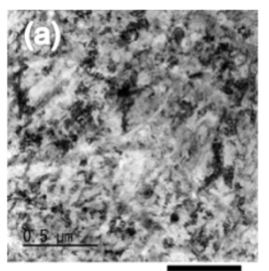

$\overline{500 \mathrm{~nm}}$

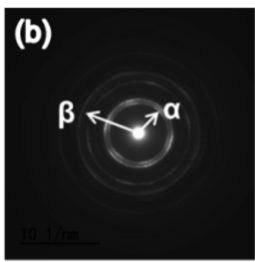

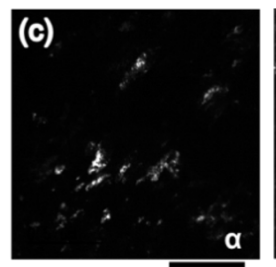

$\overline{500 \mathrm{~nm}}$

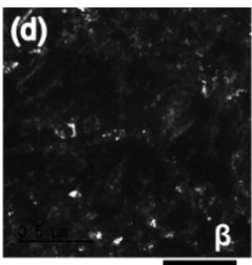

$\overline{500 \mathrm{~nm}}$

Fig.3. TEM images ((a) bright-field image, (b) SAED pattern and (c)(d) dark-field images of $\alpha$ and $\beta$ phase) Ti-6Al-7Nb alloy with STA treatment after HPT through 5 revolutions.

Figure 4 shows that Vickers microhardness increases by HPT processing with increasing number of revolutions. The HPTprocessed Ti-6Al-7Nb alloy (STA) shows high hardness values in comparison to those for the alloy without heat treatment after HPT processing. The values of the tensile strength for all HPT processed samples increased when compared with those before HPT processing. The tensile strength and elongation to fracture before HPT processing were $1050 \mathrm{MPa}$ and $22 \%$ for 
the alloy without heat treatment, and $916 \mathrm{MPa}$ and $26 \%$ for the alloy (STA), respectively. The tensile strength after 1 revolution was $1190 \mathrm{MPa}$ for the alloy without heat treatment and $1207 \mathrm{MPa}$ for the alloy (STA). After HPT processing through 20 revolutions, the tensile strength increased and the alloy (STA) showed a higher tensile strength of $1350 \mathrm{MPa}$ than $1255 \mathrm{MPa}$ in the alloy without heat treatment. The elongation to fracture was $19 \%$ for the alloy without heat treatment and $20 \%$ for the alloy (STA) after 1 revolution, and decreased with increasing number of revolutions. The values were $2 \%$ for the alloy without heat treatment and $1 \%$ for the alloy (STA) after 20 revolutions, respectively.

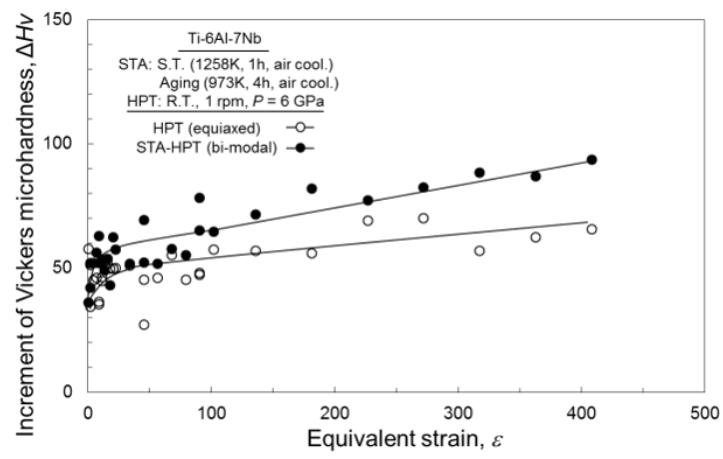

Fig.4. Increment of Vickers microhardness plotted against equivalent strain of Ti-6Al-7Nb alloy without heat treatment and with STA before and after HPT processing.

\subsection{Microstructure and mechanical properties of Ti-6Al-7Nb alloy (STQ) after HPT}

Figure 5 shows the SEM images at the center and edge of the HPT-processed Ti-6Al-7Nb alloy (STQ). After HPT processing, the $\alpha$-grains are elongated to the shear direction of the HPT processing. The changes in the grain shapes at the edge of the HPT-processed disks are more intense than that at the center of disks. The-fraction of the elongated grains increases with the increasing number of revolutions at the edge of disks. It was difficult to observe the changes in the grain shapes in the martensitic $\alpha^{\prime}$-phase because of the fine structure.

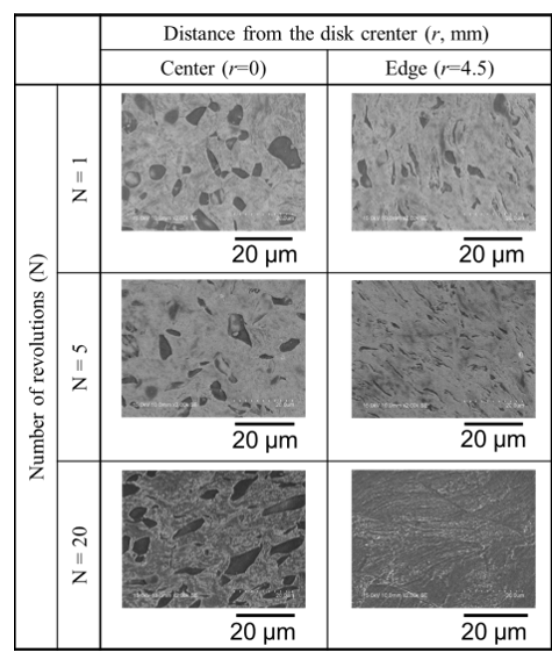


Fig. 5 SEM micrographs of disk center and edge for Ti-6Al-7Nb alloy (STQ) after HPT at different numbers of revolutions.

TEM micrographs for Ti-6Al-7Nb alloy (STQ) after 5 revolutions are shown in Fig.6. The microstructure is inhomogeneous after 1 and 5 revolutions, as shown in Figs.6. Ultrafine grains with several hundred nm in size are visible in some areas of the disks, while large grains with a few $\mu \mathrm{m}$ in size cover a majority of the sample. The microstructure is homogeneous after 20 revolutions consisting of only ultrafine grains. The grain size was $200 \mathrm{~nm}, 100 \mathrm{~nm}$ and $70 \mathrm{~nm}$ after 1 , 5 and 20 revolutions, respectively. The grain refinement was achieved by HPT processing.

(a)

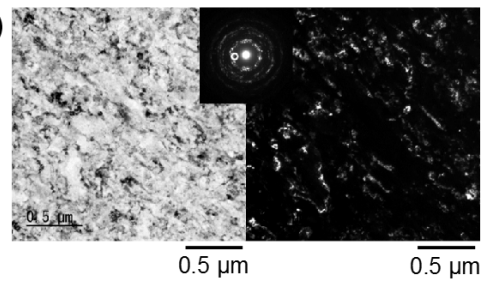

(b)

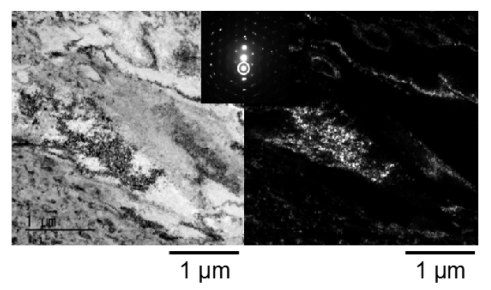

Fig.6 TEM micrographs of (a) fine grains and (b) large grains for Ti-6Al-7Nb alloy (STQ) after HPT through 5 revolutions.

The average value of the hardness before HPT was $340 \mathrm{HV}$ and increased with the increasing number of revolutions, as shown in Fig.7. The maximum value of $395 \mathrm{HV}$ was achieved after HPT processing. However, as the hardness level is similar between 5 and 20 revolutions, the hardness reached saturation after 5 revolutions. The tensile strength and elongation to fracture before HPT processing were $1100 \mathrm{MPa}$ and $23 \%$, respectively. The tensile strength was increased by HPT processing and the value was $1280 \mathrm{MPa}, 1350 \mathrm{MPa}$ and $1150 \mathrm{MPa}$ after 1,5 and 20 revolutions, respectively. The increase in tensile strength after 5 revolutions is consistent with the grain refinement. The elongation to fracture of $22 \%$ at 1 revolution was almost the same as that before HPT processing. The elongation to fracture decreased to $4 \%$ and $0 \%$ after 5 and 20 revolutions, respectively.

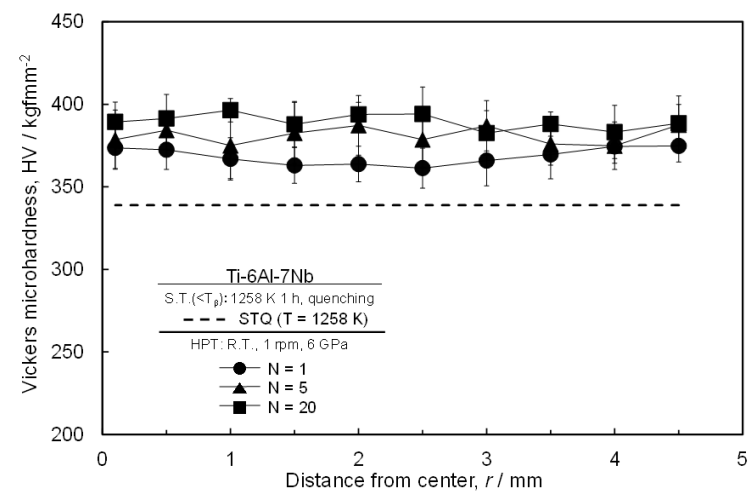

Fig.7 Vickers hardness for Ti-6Al-7Nb alloy with STQ before and after HPT processing.

\subsection{Effects of initial microstructure on resultant microstructure and mechanical properties after HPT}

For Ti-6Al-7Nb alloy with all of initial microstructures, the grain size was refined with increasing number of revolutions after HPT and the minimum grain size of $\alpha$-phase of $\sim 70 \mathrm{~nm}$ was obtained after 20 revolutions. Thus, it was shown that the resultant microstructure after HPT processing through 20 revolutions reaches same grain size even if the initial 
microstructure is different. The maximum tensile strength of Ti-6Al-7Nb alloy (STA) and (STQ) after HPT processing was $1350 \mathrm{MPa}$ and this is higher than $1250 \mathrm{MPa}$ of the alloy without heat treatment. It was clear that the HPT processing to Ti$6 \mathrm{Al}-7 \mathrm{Nb}$ alloy with the bi-modal microstructure is effective to increase the strength of the alloy. The elongation to fracture decreased with increasing number of revolutions after HPT processing and there is almost no elongation after 20 revolutions in any initial microstructures. This is caused by cracks generated during HPT processing. However, for the Ti-6Al-7Nb alloy (STQ), a good balance of mechanical properties of high strength of $1280 \mathrm{MPa}$ and large elongation of $22 \%$ was obtained after HPT processing through 1 revolution.

\section{$\underline{\text { 4. Conclusions }}$}

A Ti-6Al-7Nb alloy with three different initial microstructures was processed by HPT processing and the resultant microstructure and mechanical properties after HPT processing were investigated. After HPT processing through 20 revolutions, the grain size was refined to $\sim 70 \mathrm{~nm}$ in any initial microstructure. The alloy with bi-modal microstructures showed a higher tensile strength of $1350 \mathrm{MPa}$ than that of $1250 \mathrm{MPa}$ in the alloy with equiaxed microstructure after HPT processing. In addition, a high strength of $1280 \mathrm{MPa}$ and a large elongation of $22 \%$ were obtained for Ti-6 Al-7Nb alloy with the bi-modal microstructure consisting of $\alpha$-phase and acicular $\alpha$ '-phase after 1 revolution. It was found that large strength and elongation of the Ti-6Al-7Nb alloy were simultaneously achieved by HPT processing.

\section{Acknowledgsments}

This work was supported by the Japan Science Promotion Society (Giant-in-Aid for Young Scientist B, No.15K20473). The alloy was processed at the International Research Center on Giant Straining for Advanced Materials (IRC-GSAM) at Kyushu University.

\section{References}

1. R.Z. Valiev, Y. Estrin, Z. Horita, T.G. Langdon, M.J. Zechetbauer, Y.T. Zhu, JOM 58 (2006) 33-39.

2. Y.C. Wang and T.G. Langdon, J. Mater. Sci. 48 (2013) 4646-4652.

3. M. Janeček, J. Stráský, J. Č́́žek, P. Harcuba, K. Václavová, V. V. Polyakova, I. P. Semenova, Metall. Mater. Trans. A 45 (2014) 7-15.

4. T. S. Pinheiro, J. Gallego, C. Bolfarini, C. S. Kiminami, A. M. Jorge Jr., W. J. Botta, Int. J. Mater. Res. 15 (2012) $792-795$.

5. M. Ashida, P. Chen, H. Doi, Y. Tsutsumi, T. Hanawa, Z. Horita, Mater. Sci. Eng. A 640 (2015) 449-453.

6. P. Chen, M. Ashida, H. Doi, Y. Tsutsumi, Z. Horita, T. Hanawa, Mater. Trans. 57 (2016) 446-458. 